\title{
REMINISCENCIA DE TEMAS GRECO-LATINOS EN EL REPERTORIO AMERICANO
}

\author{
María Esther Conejo Aróstegui
}

\begin{abstract}
RESUMEN
La influencia grecolatina, de acuerdo con Gilbert Highet, se produce de diversas maneras en los poetas y escritores europeos. En este artículo, sus preceptos se aplican a tres publicaciones que aparecen en el Repertorio Americano: una de Juana Ibarbourou, otra de Víctor R. Haya de la Torre y otra de Aldoux Huxley, con el fin de verificar tal influencia.
\end{abstract}

\begin{abstract}
According to Gilbert Highet, the classical influence is detected in many ways in the european poets and writers. His ideas are applied to three publications appeared in the Repertorio Americano, a magazine, under the names of Juana Ibarbourou, Víctor R. Haya de la Torre and Aldoux Huxley, in which such an influence is found.
\end{abstract}

Al estudiar la influencia greco-latina en innumerables poetas europeos, Gilbert Highet (1970: 156) hace el siguiente descubrimiento:

Los más intensos entre los grandes poetas europeos a menudo traducen o imitan expresiones memorables de la poesía griega o latina (Las traducciones son de la autora).

Aclara Highet que algunos críticos y lectores creen que hacer lo anterior denota "falta de originalidad", pero les sale al paso afirmando:

La verdad es que de la citación de bellas palabras nace el significado más profundo, y agrega una nueva belleza, la belleza de la reminiscencia (156).

De esta manera, el significado del poema es enriquecido en muchos aspectos. Lo que Highet afirma aquí para poetas europeos, es perfectamente aplicable para poetas latinoamericanos.

En el Repertorio Americano, editado por don Joaquín García Monge, encontramos numerosas instancias de eso que Highet llama reminiscencias greco-latinas. De entre ellas hemos seleccionados tres excelentes ejemplos en que se demuestra que, efectivamente, el significado de la nueva creación se enriquece en diversas formas al acudir a la fuente clásica.

Vale apuntar, asimismo, que las reminiscencias greco-latinas las hemos encontrado no solamente en la poesía, sino que aparecen en todos los géneros literarios y en los más diversos campos del saber y del actuar humanos. 
Para ser consistentes, sin embargo, nuestro primer ejemplo es de poesía, de la poeta uruguaya Juana de Ibarbourou, quien publica en el Repertorio Americano una desafiante creación de tema mitológico que por su brevedad transcribimos a continuación:

\title{
Rebelde
}

\author{
Caronte: Yo seré un escándalo en tu barca. \\ Mientras las otras sombras recen, giman o lloren, \\ Y bajo tus miradas de siniestro patriarca \\ Las tímidas y tristes en bajo acento oren, \\ Yo iré como una alondra cantando por el río \\ Y llevaré a tu barca mi perfume salvaje \\ E irradiaré en las ondas del arroyo sombrío \\ Como una azul linterna que alumbrará en el viaje. \\ Por más que tú no quieras, por más guiños siniestros \\ Que me hagan tus dos ojos, en el terror maestros, \\ Caronte, yo en tu barca seré como un escándalo. \\ Y extenuada de sombra, de valor y de frío \\ Cuando quieras dejarme a la orilla del río \\ Me bajarán tus brazos cual conquista de vándalo (Ibarbourou 1920: 180).
}

En su soneto, la poeta uruguaya crea un contrapunto: toda la siniestra pintura de Caronte -ese patriarca sombrío con ojos de terrible mirada expertos en el terror, el barquero del Hades- es contrastada eficazmente con la pintura de sí misma como "Alondra cantando por el río ..." segura y desafiante. La reminiscencia de todo lo que Caronte significa, le da profundidad y plasticidad a la idea que la poeta pinta de la muerte.

Igualmente establece una total antítesis entre las otras almas que lleva el temible barquero, tímidas, tristes, gimiendo, llorando, orando, mientras ella, no sólo va cantando, sino que irradia luz para alumbrar el viaje, e inunda la barca con su "perfume salvaje". La rebeldía del título del soneto se transluce en cada verso. El río Aqueronte, con su barca y su barquero, se despliegan con toda la sombría frialdad que tuvo en los tiempos clásicos. La unión de ambos mundos es perfecta. Y no cabe duda de que la reminiscencia le da dimensiones mucho más amplias al poema y es base ideal para los contrastes que la poeta destaca.

Un ejemplo típico de reminiscencia griega en el campo político lo encontramos en el ensayo publicado por Víctor Raúl Haya de la Torre (1947: 220-1), famoso político humanista peruano, que residió en Costa Rica varios años y apreció mucho la democracia en que aquí se vivía. El artículo hace comparación entre la democracia ateniense y las democracias en que luchaban en América Latina por establecerse o mantenerse. En él se refiere a dicotomías como pueblo y oligarquía, oligarquía y cultura, democracia y juventud, teniendo cuidado de hacer siempre énfasis en el pueblo soberano. Para ello, hace evocación de un pasaje de la "Memorabilia” de Jenofonte, en la que Alcibíades gran estratega ateniense - hace una pregunta a su tutor "Dime Pericles: ¿Puedes enseñarme qué es la Ley?" A lo que Pericles respondió: “Alcibíades, no hay mayor dificultad acerca de lo que tú deseas. Tú quieres saber qué es ley: Leyes son las reglas aproba- 
das y establecidas por la mayoría en asamblea, por las cuales se declara lo que se debe y lo que no se debe hacer". Haya de la Torre recuerda, comparando: "Los parlamentos de las democracias clásicas, se celebraban al aire libre, bajo la bóveda del cielo, sin curules, carpetas, ni timbres, ni dietas. Pero eran, como las de hoy, asambleas representativas del pueblo para acordar y promulgar leyes por voto democrático de mayorías". Sin embargo, también desde aquellos tiempos — dice don Víctor Raúl— viene la lucha entre Pueblo y Oligarquía, entre mayoría popular y pobre y minoría aristocrática y rica. Y es bien sabido que todo gobierno oligárquico es enemigo de la cultura popular. La oligarquía -agrega- necesita de la ignorancia y el envejecimiento moral y mental del pueblo para subsistir como sistema; la democracia necesita de la cultura y de la juventud moral y mental del pueblo para permanecer y progresar. El pueblo debe defender sus leyes y escoger bien sus líderes, en todo tiempo y en todo lugar. Para estas tierras de Indoamérica, Sarmiento, maestro de escuela que actuó en política, supo dar la fórmula en una frase digna de Pericles: "El pueblo es soberano, pues a educar al soberano". Es evidente el empleo de la reminiscencia del pasaje de Jenofonte, como paradigma, como ejemplo edificante a seguir en preceptos de uno de los hombres más preclaros de la democracia ateniense como lo es Pericles, el cual le confiere validez a las sugerencias suscitadas por la situación presente en los diversos países de América, así como el uso de la cita de Sarmiento también muy efectiva, como revaloración de ideas griegas aplicables hoy.

En algunos casos, unas pocas palabras de alusión apta son suficientes para producir la reminiscencia.

Un excelente ejemplo de esto lo vemos en el ensayo de Aldous Huxley titulado "Pigmalión contra Galatea" (1931: 186-200), sobre el mundo social y económico del momento, publicado en 1931 en el Repertorio Americano. Pigmalión -en el mito griego original - fue un insigne escultor, que un buen día le dio forma a una preciosa ninfa, a Galatea, y habiéndose enamorado de su obra, le suplicó a Afrodita, la diosa griega del amor, que le infundiera vida para poder realizar su amor; la diosa accedió y vivieron ambos muy felices. Conociendo el mito griego de Pigmalión, la sola palabra "contra" en el título del ensayo de Huxley nos da inmediatamente una idea de incongruencia, de algo que está al revés. Y es eso precisamente lo que Huxley espera de sus lectores, obteniendo así una doble ventaja en el empleo del paradigma mitológico griego, pues ofrece, por un lado, la imagen plástica del problema económico-social que aborda extensamente en su ensayo, y por otro, al introducir el provocativo "contra", incrementa el interés del lector alerta y conocedor de los temas clásicos. En su argumentación, Huxley explica que el hombre, "el vencedor de la naturaleza, ha sido derrotado por el arte, por las propias artes que él mismo creó con el objeto de vencer a aquélla. La humanidad se tambalea hoy ante los golpes que recibe en esa desastrosa lucha con las fuerzas organizadas de su propia inteligencia". La maquinaria de producción en aquél momento, da abundancia de productos, pero ¿por qué hay ejércitos de desocupados en todos los países industriales del mundo? Porque hay sobreproducción ... Y hay sobreproducción porque esas artes de nuestra invención, mediante las cuales hemos dominado a la naturaleza, nos están a la vez dominando. El inventor del artefacto -el hombrese convierte en víctima de éste. La evocación del mito, de Pigmalión y Galatea con la importantísima variante "contra" que hace Huxley resulta así altamente efectiva para probar su tesis, en un problema de actualidad. 
"El lector que sabe y puede reconocer estas evocaciones fácilmente, obtiene no sólo una comprensión más completa del asunto, sino un placer más completo que el que no lo hace" (Highet 1970: 158). Además de una escena más viva, el lector "conocedor" obtiene todo el trasfondo que las evocaciones representan, lo que le permitirá extraer toda la fuerza de un evento, y ennoblecerán tanto al autor como a sus creaciones.

\section{Bibliografía}

Highet, Gilbert. 1970. The Classical Tradition. Oxford University Press, Inc.

Ibarbourou, Juana de. 1920. "Rebelde". Repertorio Americano 1 (12): 180.

Haya de la Torre, Víctor Raúl. 1947. "Dime Pericles ¿Puedes enseñarme qué es la ley?”. Repertorio Americano. 43 (14): 220-1.

Huxley, Aldous. 1931. "Pigmalión contra Galatea”. Repertorio Americano 23 (12): 177, 186-200. 